\title{
8. From Applied Anthropology to an Anthropology of Engagement: Japanese anthropology and Australianist studies
}

\author{
Sachiko Kubota \\ Kobe University, Japan
}

In this chapter, I share my observations of the different natures and historical developments of anthropology in Australia and Japan. My main focus is on applied anthropology (cf. Van Meijl, this volume). For a long time, and for historical reasons, applied anthropology has been viewed sceptically in Japan. My chapter details how this has begun to change through the influence of Professor Nic Peterson. I trace this emergent change in attitude in Japanese anthropology by illuminating how the study of Australian Aboriginal people generally and Nic Peterson's work and contacts in particular have changed hitherto prevalent ideas in Japan.

I begin with a review of developments in Japanese anthropology from the late nineteenth century onwards, with particular reference to questions of colonisation, applied anthropology and ethical engagement. I then explore the influence of Australian and Aboriginal anthropology in general, by using Elkin as an example. This is followed by a description of how Nic Peterson's work on practical anthropology, such as commitment to land rights, native title, marine tenure and citizenship rights, has significantly contributed to the rise in research with direct social applications within contemporary Japanese anthropology. I conclude by commenting on the increasing popularity of an 'anthropology of engagement' within the Japanese academy, honouring the continuing vitality of the reorientation that Nic Peterson helped to facilitate.

\section{Historical Characteristics of Japanese Anthropology}

The unique history of Japanese anthropology is intimately intertwined with Japan's colonial history. As Shimizu (1999) elaborates, Japan is the only Asian country that did not experience European colonisation; quite to the contrary, Japan itself colonised other Asian and Micronesian countries. Parallel with 
the situation in European countries, Japanese anthropology also developed in close relation to its colonial history. The first Japanese academic anthropological association, the Anthropological Society, was established in Tokyo in 1884. This happened early in the Meiji period, not long after Japan opened itself in 1868 after the long feudal Edo period in an effort to seek the world's recognition of the country as a modern state. The members of the association were mostly amateurs and the focus of the association was very broad, including on human evolution, physical anthropology, folklore and race studies. One of the most important debates of the time related to the geographical, evolutionary and historical origins of the Japanese race, and this debate led to a close study of the Ainu, the Indigenous people of Japan. As the main research interest was about origins, the Ainu were treated as a collective group disregarding all local differences, and the then contemporary circumstances of Ainu people were of no concern (Shimizu 1999). This trend of historical and prehistorical study continued for a long time.

With its establishment as a modern nation-state, Japan developed imperial interests in Asia and Oceania, colonising Taiwan, South Sakhalin, Korea and Micronesia between 1895 and 1922. Various anthropological studies were conducted in these occupied areas during and after this period. The Japanese military invasion of China and South-East Asia dramatically increased opportunities for field research and changed the nature of Japanese anthropology, as it created an urgent need for practical knowledge of the colonised peoples and their societies. Numerous research institutes were established in the colonies as well as in Japan, including the Asian Research Institute in 1938, the Research Committee on Asian Issues in 1940, the Northeast Research Institute in Mongolia in 1944, the Resource Research Institute in Seoul in 1945 and the South Pacific Research Institute in Taiwan in 1943-amongst others. Japanese anthropologists also became actively involved in the war efforts. The Ethnic Research Institute was established in 1943 and successfully lobbied for funding to recruit anthropologists and dispatch them to investigate peoples and cultures in the areas occupied by Japan (Nakano 1999).

Japan's 1945 defeat in World War II had a devastating effect on Japanese anthropology. Institutions established during the war were dissolved and anthropologists were blamed openly for their cooperation with the state and the military. The discipline needed to rehabilitate itself and recover its moral moorings. Immediately following the war, this expressed itself in the desire of practitioners to recover the scientific value of anthropological research. As a result, anthropologists categorically refused to become engaged in issues such as ethnic movements, ethnic problems and ethnic policies as topics of research inquiry. In other words, a clear separation was drawn between anthropological practices and political situations, and anthropologists actively avoided research that engaged in an applied way with the practical needs of society. 
The discipline managed to survive the war, eventually transforming into a new 'cultural anthropology', which was established within the universities. In one way, the end of the war was a liberation for many anthropologists. Western anthropological knowledge, which had been prohibited during the way, became freely accessible. Anthropologists after the war accepted and shared the pure and supposedly neutral and objective academic values as the basis of their discipline, while continuing a deep reflection on the activities of the discipline during the war. For a long time after the war, Japanese anthropologists did not study the country's former colonies and, similarly, domestically, Ainu issues were intentionally neglected as they became even more politicised in the postwar context. Ainu activists were starting the struggle for their rights and, as this was seen as a political movement, Japanese anthropologists generally displayed negative attitudes towards applying anthropological knowledge to practical issues, even as late as the 1980s (Shimizu 1999). This was particularly true in, but not exclusive to, the Ainu context.

Gradually, beginning in the 1950s, anthropologists began to return to research in Japanese villages and then in South Asia, North America and Taiwan in the late 1960s, followed by research in Melanesia and Polynesia. During the 1970s, the Japanese economy finally recovered completely and it took until then for Japanese anthropologists to return to the former Japanese colonies of China, Mongolia, Siberia, Korea and Micronesia (Shimizu 1999).

In regards to Australia, there had been several minor research projects conducted by Japanese anthropologists before World War II-based mostly on library studies, including by Tsuboi (1892) and Nishimura (1930), amongst others. Although Japan did not colonise Australia, it took a long time for Japanese anthropologists to commence field research there again. There were a number of reasons for this. On the one hand, Japan had bombed Australia during the war and took many Australians hostage; and on the other, Australia's White Australia Policy made working in Australia difficult. It was not until the 1960s that the first Japanese fieldwork began there, and not until the 1970s that research in the country increased significantly, with a substantial linguistic study commenced by Tsunoda, research into Aboriginal education by Shinpo and an examination of the contemporary Aboriginal situation by Suzuki (see Iijima 2006).

The National Museum of Ethnology in Osaka was established in 1974 as the centre for anthropological research and its promotion. And in the early 1980s, Professor Shuzo Koyama and his research team from the museum perceived a need for Australian material culture artefacts and associated research, which were missing from the museum at that time. A handful of materials related to Australian Aborigines had been donated to the museum by Tokyo University, but they were far from a systematic collection. Koyama visited The Australian National University in his attempts to begin research aimed at forming a 
collection of material culture for the museum, and it was Nic Peterson who helped him to get into the field and gave him practical advice. Their cooperative relationship has continued ever since. Various Japanese scholars who were part of Professor Koyama's research team started to visit Australia and Nic Peterson acted as adviser to and collaborator with the team.

During these occasions, the Japanese researchers had the chance to learn about Australian anthropological standards and to get up-to-date information on the contemporary research situation in Australia. It was on the basis of Nic Peterson's advice that the Japanese research team considered a wider range of research topics - for example, territorial issues and land rights, gender perspectives, urban studies, diet studies, media studies, visual anthropology and national policy perspectives (Koyama and Kubota 2002). Professor Peterson's immersion in Australian anthropology and his personal experience of the value of applied anthropology were of crucial importance in facilitating further developments in Japanese anthropology over the next three decades. Before commenting further on these developments, it is worth briefly examining the changing nature of engagements between Australian anthropology and its wider social context.

\section{Australian Anthropology and its Applied Tendency}

Anthropological studies of Aboriginal people in Australia have a long and deep history. From the end of the nineteenth century, intensive studies of the people who were then believed to be dying out had been undertaken, and although the sense of urgency that initially motivated those studies has faded, research into Aboriginal Australia has continued. One means of examining the changing context of that study is through the analysis of an influential ethnographic text, The Australian Aborigines by A. P. Elkin, first published in 1938. This book has been revised six times, with the last revised version published in 1979. The structure, contents and intended readers of the book changed over the years, and these changes clearly correlate with social changes surrounding both the circumstances of Aboriginal people and the attitudes that wider society took towards them. In my own work, I have illustrated how these changes reflect a practical orientation towards society that is characteristic of Australian anthropology (Kubota 2005).

Although Elkin's work is not directly connected to the works of Nic Peterson, Peterson's work has always had a strong emphasis on applied matters. Peterson's works on native title(with Rigsby 1998), land rights (1976, 1981) and citizenship (with Sanders 1998), among others, indicate the applied nature of 
his research. It helps us - especially people who are not familiar with Australian anthropology - to understand this kind of applied nature in the relationship to Australian anthropology, which is strikingly illustrated in Elkin's works.

Since the 1870s, anthropological studies of Aboriginal kinship and religious systems have been painting Aboriginal societies and cultures as complex and rich, illustrating in the process the necessity of intensive fieldwork. In 1925, the first department of anthropology was established at Sydney University, headed by Professor Radcliffe-Brown, and the following year saw the beginnings of systematic Australian anthropological research on Aboriginal people. Research results demonstrated the richness of Aboriginal culture and were made public through publications and lectures. In 1931, Elkin became the second professor in the department and it was in this climate of public dissemination of research results that Elkin's book was published.

In the preface of the first edition, Elkin notes that his aim is to improve white Australians' understanding of, attitudes towards and treatment of Aboriginal people. This illustrates Elkin's understanding that the white Australian general public, students and missionaries, and administrators who dealt with Aboriginal people were the intended readers of his book. The first edition contained 10 chapters: beginning with an introduction, the second to fifth chapters were devoted to social organisation, and the sixth to tenth chapters emphasised beliefs, world views and rituals. This structure and contents are quite typical for early twentieth-century anthropological writing in Australia, when social organisation and religion were the most researched topics in Aboriginal Studies.

In the 1940s, interests in and a need for the study of Aboriginal society and peoples expanded with growing overseas criticism, and new departments of anthropology were established at other universities in Australia (at The Australian National University in 1949, at the University of Western Australia in 1956, at Monash University in 1963 and at the University of Queensland in 1957). In 1962, the then Australian Institute of Aboriginal Studies (now called the Australian Institute of Aboriginal and Torres Strait Islander Studies, AIATSIS) was established in response to the lobbying of Indigenous and nonIndigenous activists, and by anthropologists who were appealing for extensive research into contemporary Aboriginal circumstances. About that time, protests and political movements seeking the equal treatment of Aboriginal people also grew.

The third revised edition of Elkin's book was published in 1954. In this version, he added two chapters dealing with Aboriginal art and one further chapter at the very end of the book titled 'Epilogue: The Aborigines on the March'. He noted in the sixth edition, published in 1979, that the title of the chapter referred to Aboriginal people marching for their citizenship rights (Elkin 1981: 
$\mathrm{x}$ ). This new concluding chapter discusses contact history, policy changes and Aboriginal responses to them. This chapter was rewritten and changed for every reprint and revised to reflect any changes in the Aboriginal situation. In the final version, Elkin writes that Aboriginal people are now emerging with rights as citizens, showing how he was concerned to represent the practical situation of Aboriginal people.

The later changes also demonstrate that Elkin started to include Aboriginal people as readers of his book. He writes that 'mixed blood' Aborigines and even some 'full-bloods' have been 'seeking to realize and emphasize their identity through their own cultural heritage' (Elkin 1981: vi). He wrote:

[T] hey have lost essential elements of that heritage, that living link with their cultural past...[and] as Aborigines read this book, I hope it will help them to gain not only pride in their indigenous culture, but a base from which to face the realities of their situation. (Elkin 1981: vi)

In the preface to the fifth and sixth revisions, he also dedicated the book to Aboriginal people, who were struggling to obtain equal citizenship at that time (Elkin 1981).

Elkin's often-revised book is one example of how anthropological writing is influenced by contemporary social context and how it can somewhat alter its course. It is not unusual to see mainstream politics having a lot to do with Aboriginal matters in Australia (see, for example, Partington 1996). There are always attempts to apply academic knowledge to current Aboriginal issues (a recent example is Altman and Hinkson 2007). This shows that anthropological literature in Australia has a strong connection to practical social matters and clearly resonates with social changes. This tendency towards socio-political comment and engagement, especially on Aboriginal matters, could be called a tradition in Australian anthropology, which is also clearly seen in the directions and contents of the research of Nicholas Peterson.

\section{Changes in Japanese Anthropology}

Since the 1980s, it has gradually become obvious that interest in practical anthropology is growing, especially among the younger generations in Japan. After the 'writing culture shock', which also affected Japan, anthropologists were seeking ways to find new positions. Sentiments grew that anthropology does not necessarily need to be based on pure scientific value; rather, anthropologists began to prefer to convey applied research to meet the practical needs of society, wanting to engage with real life. In contrast with anthropologists engaged in other research areas and in part because of Nic Peterson's input, the Japanese Australian Research Team always had a strong tendency towards an applied 
nature in their work and always viewed that characteristic positively. They actively engaged with the needs and development projects of the field and tried to return their research outputs to the community (Kubota 2007).

My own research is a case in point. Although I started my research on social change among Yolngu people in north-east Arnhem Land from a gender point of view (Kubota 2006), I gradually began to expand to more practical topics. Recently, I extended my interest to the concept of 'indigeneity' in relationship to the policies of the nation-state and international discourse. In 2004, I organised a three-year study group at the National Museum of Ethnology in Osaka on the expansion of Indigenous ideology into Asia and Africa, as well as in settled countries such as Australia. In this project, diverse forms of acceptance, resistance or rejection of Indigenous ideology were documented and analysed, as we came to the understanding that the idea of indigeneity is a key concept for analysing current socio-political situations. Compared with the claims of some other national minority groups, Indigenous claims have, of course, a significant moral advantage, which has been strengthened by the growth of the international discourse on Indigenous rights. The transnational networks formed by Indigenous people mean that now even groups such as the Ainu have been drawn into them, with positive political effects on the Japanese Government's policies directed towards them (Kubota and Nobayashi 2009). With such research, anthropologists often find themselves engaging with people's needs as they are part of international discourses and are expected to interpret back to the people in the field (Kubota 2007). I am further expanding the research projects on Indigenous negotiation with the nation-state at the time of writing.

The other project currently being undertaken in conjunction with the National Museum of Ethnology, Osaka, is 'The Family Tree Project' headed by Professor Sugito. Its aim is to develop a fieldnote database software tool to be utilised to automatically write kinship trees or diagrams. The program has a strong applied element and tries to meet the needs of Indigenous communities to store and utilise their Indigenous knowledge (Sugito 2008). The software is shared by many Japanese and Australian anthropologists and researchers engaged in the field as well as being used as a basic research tool for practical needs above and beyond purely academic ones.

Applied anthropology was marginalised in Japan for a long time. Negative attitudes towards it are, however, changing rapidly and now researchers are increasingly becoming interested in applied issues and are wanting to engage in research topics that are related to local people's social and political needs. For example, the study of Ainu, the Japanese Indigenous population, and their current situation, including their cultural struggle, which has not been the main topic of study for a long time, is now burgeoning, even if most of the 
research still concentrates on historical and linguistic studies. With the Japanese Government currently in the process of negotiating ways to recognise Ainu as Indigenous Japanese, and also with Ainu people's strong appeal, anthropology is facing the requirement to engage in an applied way and focus on social needs (Kubota and Nobayashi 2009).

Australian anthropology, particularly as it relates to Aboriginal people, has been and continues to operate as a good example for us. In his role as a mentor and research facilitator, Nic Peterson introduced many Australian scholars to Japan, encouraging them to visit and share their knowledge for periods of up to a year. These academic visitors have included Margaret West, Will Arthur, Luke Taylor, Ian Keen, Franchesca Cubillo, Djon Mundine, Avril Quail, Julie Finlayson and David Martin, among others. Discussions and interactions with these visitors have encouraged Japanese anthropology focused on Aboriginal studies to take a strong turn towards a practical involvement in society's needs. Nic Peterson also helped to organise international symposia and conferences in Osaka; one was 'Commoditization of Hunting and Gathering Societies', in 1988 (Peterson and Matsuyama 1991), while another was the Eighth Conference on Hunting and Gathering Societies (CHAGS8) in 1996 (Peterson 1999). Nic Peterson facilitated a special public exhibition called 'Aboriginal Australia - 50,000 Years of Hunters and Dreaming' at the National Museum of Ethnology in 1991. He assisted with planning the exhibition, with sourcing existing works and commissioning new ones and with providing opportunities for Aboriginal artists to visit the museum during the exhibition (Koyama et al. 1991). This exhibition attracted more than 30000 visitors, giving the Japanese public a chance to see Aboriginal people and their culture close up. Under the influence of Australian anthropology and Nic Peterson in particular, the Australian research team in Japan has been able to play a vital leadership role in the development of a vibrant, contemporary and uniquely Japanese 'anthropology of engagement'. ${ }^{1}$

\section{References}

Altman, J. and M. Hinkson (eds), 2007. Coercive Reconciliation-Stablise, Normalise, Exit Aboriginal Australia. Sydney: Arena.

Elkin, A. P. 1948 [1938]. The Australian Aborigines. Sydney: Angus and Robertson.

\footnotetext{
1 'Anthropology of engagement' is the term used by David Martin at the Applied Anthropology Outside Universities workshop held at the National Museum of Ethnology, Osaka, in 2009. Many of the anthropologists attending the meeting found the term quite appropriate for use in contemporary Japanese anthropology.
} 
Elkin, A. P. 1981 [1979]. The Australian Aborigines. Sydney: Angus and Robertson.

Iijima, S. 2006. Australian Aboriginal studies in Japan, 1892-2006. Japanese Review of Cultural Anthropology 7: 51-70.

Koyama, S. and S. Kubota (eds), 2002. Indigenous People of Multicultural Society. Kyoto: Sekai-shiso-sha.

Koyama, S., Matsuyama, T., Kubota, S., Kubo, M., Sugito, S. and Matsumoto, H. (eds), 1991. Aboriginal Australia-50,000 Years of Hunters and Dreaming. Osaka: Sankei-shinbun-sha.

Kubota, S. 2005. Indigenous people - changing ethnography. In S. Yamashita (ed.) Cultural Anthropology-20 Models to Connect Modern to Classics, pp. 92-116. Kyoto: Koubundo.

Kubota, S. 2006. Gender Studies on Aboriginal Society-Indigenous People, Women and Social Change. Kyoto: Sekai-shiso-sha.

Kubota, S. 2007. Paradox of sacred-secret objects in the local museumsAboriginal practices and researchers' engagement. Cultural Anthropology 70 (4): 484-502.

Kubota, S. and A. Nobayashi (eds), 2009. Who is Indigenous? Kyoto: Sekai-shisosha.

Nakano, K. 1999. Japanese colonial policy and anthropology in Manchuria. In J. van Bremen and A. Shimizu (eds), Colonial Anthropology in Asia and Oceania, pp. 245-65. Richmond, UK: Curzon.

Nishimura, S. 1930. Race. In T. Nakama (ed.), World Geography and Custom Compendium. Volume23. Tokyo: Shinko-sha.

Partington, G. 1996. Hasluc versus Coombs-White Politics and Australia's Aborigines. Sydney: Quakers Hill Press.

Peterson, N. (ed.) 1976. Tribes and Boundaries in Australia. Canberra: Australian Institute of Aboriginal Studies.

Peterson, N. (ed.) 1981.Aboriginal Land Rights: A Hand Book. Canberra: Humanities Press, Australian Institute of Aboriginal Studies.

Peterson, N. 1999. Hunter-gatherers in first world nation states-bringing anthropology home. Bulletin of the National Museum of Ethnology 23 (4): 847-61. 
Peterson, N. and T. Matsuyama (eds), 1991. Cash, commoditization and changing foragers. Senri Ethnological Studies No. 30, National Museum of Ethnology, Osaka.

Peterson, N. and B. Rigsby (eds), 1998.Customary Marine Tenure in Australia. Sydney: University of Sydney.

Peterson, N. and W. Sanders (eds), 1998.Citizenship and Indigenous Australians. Cambridge: Cambridge University Press.

Shimizu, A. 1999. Colonialism and the development of modern anthropology in Japan. In J. van Bremen and A. Shimizu (eds), Anthropology and Colonialism in Asia and Oceania, pp. 15-171. Richmond, UK: Curzon.

Sugito, S. 2008. Applied anthropological study on utilization of kinship database and family tree - application and development of support. Report for fund-inaid for scientific research. <http://study.hs.sugiyama-u.ac.jp/2005rec/>

Tsuboi, S. 1892. Archeology and anthropology. Tokyo Gakugei Zasshi 9 (124): $8-13$. 